\title{
EFFECTS OF RELAXING TIME WINDOWS ON VEHICLE ROUTING AND SCHEDULING
}

\author{
Ali Gul Qureshi **, Eiichi Taniguchi*** and Tadashi Yamada****
}

\section{Introduction}

With the increase in the economy and industrial activities, large cities are experiencing increase in transportation requirements in terms of both passengers and freight. A high proportion of total goods movement occurs within cities ${ }^{1)}$ and most of this movement is based on road transport. Traffic congestion, noise, vibrations, emissions of NOx, SPM, $\mathrm{CO}_{2}$ and other environmental problems, traffic accidents, loading and unloading on streets are typical problems caused by the road-based freight transportation in urban areas.

Innovations in logistics such as Just-In-Time (JIT) systems, constraining time windows and e-commerce have further aggravated urban freight related problems. Increase in e-commerce, especially Business to Consumers (B2C) increases the negative effects on environment and traffic conditions, unless a major proportion of consumers use $\mathrm{B} 2 \mathrm{C}$, so that the reduced shopping trips may have considerable positive impact ${ }^{2}$.

City logistics is a branch of urban management system which deals with the urban freight related problems and their solutions. Measures such as route optimization, ideal location of logistic terminals and depots, load factor controls and cooperative delivery systems etc. are used for taming the effects of above-mentioned problems. Freight vehicles with their higher PCU (Passenger Car Unit) value, play an important part in the design and management of a road network. The behavior of logistic companies under pressure of consumer satisfaction must be taken into consideration at infrastructure planning and management level. How the freight vehicle movement will change if travel times (due to congestion or truck ban) or travel costs (due to toll tax etc.) of some of the links are changed. This and many similar questions must be assessed before taking any planning and management steps.

Vehicle Routing and scheduling Problem with Time Windows (VRPTW) is a typical tool, used to investigate a variety of city logistics measures. In Vehicle Routing and scheduling Problem with Hard Time Windows (VRPHTW), delivery is not possible outside the customer specified time windows. While in Vehicle Routing and scheduling Problem with Soft Time Windows (VRPSTW) variant, any violation of time windows causes a penalty but the delivery is still possible. While many real logistics problems are set in soft time windows environment, most of the research is directed towards hard time windows variant of VRPTW. A possible explanation of this could be that VRPHTW would be easier to obtain exact solutions, even though tight time windows might deteriorate the traffic and environmental conditions.

This paper presents the initial results of a study, which focused on the effects of hard time windows and soft time windows on the total running time, cost of delivery, and on emissions of $\mathrm{NOx}, \mathrm{SPM}$ and $\mathrm{CO}_{2}$. A variety of time windows variants are analyzed under different scenarios based on time windows width, geographical locations of customers and link travel times. Furthermore, waiting time is considered as an integral part of the solution in any time windows settings. At this stage, heuristic solution for soft time windows is compared with heuristic and exact solution of hard time windows. As far as the authors are aware there does not exist any comparison for the variety of time windows and scenarios presented in the paper, particularly taking effects of waiting time in environmental emissions.

\section{Literature Review}

While most practical logistics problems are set in soft windows environment, the exact solution approaches until now remained focused on hard time windows variant. Mostly heuristic (approximate) solutions of

* Key words: logistics planning, vehicle routing

** Student Member of JSCE, M.E, Doctoral Student, Faculty of Engineering, Kyoto University.

C-1 Kyotodaigaku Katsura, Nishikyo,Kyoto 615-8540, Tel. 075-753-3231, Fax. 075-950-3800

*** Fellow Member of JSCE, Dr. Eng., Faculty of Engineering, Kyoto University.

C-1 Kyotodaigaku Katsura, Nishikyo,Kyoto 615-8540, Tel. 075-753-3229, Fax. 075-950-3800

**** Full Member of JSCE, Dr. Eng., Faculty of Engineering, Kyoto University.

C-1 Kyotodaigaku Katsura, Nishikyo,Kyoto 615-8540, Tel. 075-753-3230, Fax. 075-950-3800 
VRPSTW are used in city logistics related research ${ }^{3-4)}$, where the solution is required within reasonable computational time. Many researchers has focused their work on VRPTW solution based on heuristics such as tabu search ${ }^{5)-6)}$, simulated annealing ${ }^{7)}$ and genetic algorithms ${ }^{8-12)}$. Heuristic techniques are procedures that seek to find good (i.e. near exact) solutions for mathematical programming problems. While they are sometimes faster and easily implemented, yet they do not guarantee to identify the exact solution or state how close to the exact solution a particular feasible solution is ${ }^{13)}$.

With the rapid increase in computer and information technology, it has now been possible to solve the VRPHTW of limited nature to optimality by using exact solution techniques within reasonable computational time. After the earlier work of Kolen et al. ${ }^{14)}$ using dynamic programming, the body of literature on VRPHTW has been increasing with time. Most of the research has taken along two optimal approaches, namely Lagrangean relaxation ${ }^{15)-16)}$ and column generation ${ }^{17-21)}$. Column generation or DantzigWolfe decomposition, decomposes the VRPTW problem into a set partitioning master problem and an Elementary Shortest Path Problem with Resource Constraints (ESPPRC) subproblem. Many researchers have worked with various shortest path variations as subproblem, for instance, Desrochers et al. ${ }^{17)}$ used 2cycle elimination while solving shortest path subproblem, Kohl et al. ${ }^{18)}$ introduced two path cuts in their master problem whereas Irnich and Villeneuve ${ }^{19)}$ used k-cycle elimination with $\mathrm{k}>3$. Feillet et al $^{20)}$ and Chabrier $^{21)}$ used ESPPRC as the subproblem.

\section{Vehicle Routing and Scheduling Problem with Time Windows (VRPTW)}

VRPTW is defined on a directed graph $G=(V, A)$. The vertex set $V$ includes the depot 0 and the set of customers $C=\{1,2, \ldots \ldots \ldots, n\}$. With every vertex of $V$ associated a demand $d_{i}$, with $d_{0}=0$, and a time window $\left[a_{i}, b_{i}\right]$ representing the earliest and the latest possible service start times. $K$ represents the set of identical vehicles with capacity $q$. The arc set $A$ consists of all the feasible $\operatorname{arcs}(i, j), i, j \in V$. A cost $c_{i j}$ and time $t_{i j}$ is associated with each $\operatorname{arc}(i, j) \in A$. $t_{i j}$ includes the service time at vertex $i$. The objective of the VRPTW is to design a set of feasible routes of minimum cost, starting and ending at depot serving all customers exactly once. A feasible route is defined as ordered set of customer vertices, which satisfies the capacity constraint of the vehicle and time windows of customers.

Kohl et al. ${ }^{18)}$ mathematically formulated VRPTW as

$$
\min \sum_{k \in K} \sum_{(i, j) \in A} c_{i j} x_{i j k}
$$

subject to

$$
\begin{aligned}
& \sum_{k \in K} \sum_{j \in V} x_{i j k}=1 \quad \forall i \in C \\
& \sum_{i \in C} d_{i} \sum_{j \in V} x_{i j k} \leq q \quad \forall k \in K \\
& \sum_{j \in V} x_{0 j k}=1 \quad \forall k \in K \\
& \sum_{i \in V} x_{i h k}-\sum_{j \in V} x_{h j k}=0 \quad \forall h \in C, \quad \forall k \in K \\
& \sum_{i \in V} x_{i 0 k}=1 \quad \forall k \in K \\
& s_{i k}+t_{i j}-s_{j k} \leq\left(1-x_{i j k}\right) M_{i j k} \quad \forall(i, j) \in A, \quad \forall k \in K \\
& a_{i} \leq s_{i k} \leq b_{i} \quad \forall i \in V, \quad \forall k \in K \\
& x_{i j k} \in\{0,1\} \quad \forall(i, j) \in A, \quad \forall k \in K
\end{aligned}
$$

Where, $x_{i j k}$ is 1 if the vehicle $k$ travels from vertex $i$ to $j$ and 0 otherwise, and $s_{i k}$ is the service start time at vertex $i$ by vehicle $k$. $M_{i j k}$ is a big constant. Constraint set (2) enforces that every customer must only be serviced once while constraint (3) is capacity constraint. Constraints (4), (5) and (6) are flow preservation constraints. Constraints (8) and (9) are time windows constraints. 
(1) Genetic Algorithms (GA)

This study uses a genetic algorithms $(\mathrm{GA})^{9)}$ to find the approximate solution of VRPTW. In GA, initialization, population size, and genetic operators (crossover and mutation) play an important role in the solution quality. As follows gives a brief description of the GA used.

i) Initialization and Population Size: Integer valued genes were used to represent a feasible solution of VRPTW. The individual or chromosome represents a complete solution as a long chain of customer vertices where new routes/vehicles are identified either by the presence of depot or due to capacity or time window violation. Figure 1 shows a VRPSTW chromosome or population individual for a twelve customer instance and its interpretation during the algorithm for new vehicles due to presence of a depot gene or constraint violation. Two continuous variables (qsum ${ }_{0}=0$ and twroute $_{0}$ (as per eq. 10)) for each vehicles are initiated and are updated every time that vehicle travels from $i$ to $j$ according to the eq.s (11) and (12)

$$
\begin{aligned}
& \text { twroute }_{0}=\max \left[a_{0}, a_{i}-t_{0 i}\right] \\
& \text { qsum }_{j}=\text { qsum }_{i}+d_{j} \\
& \text { twroute }_{j}=\text { twroute }_{i}+t_{i j}
\end{aligned}
$$

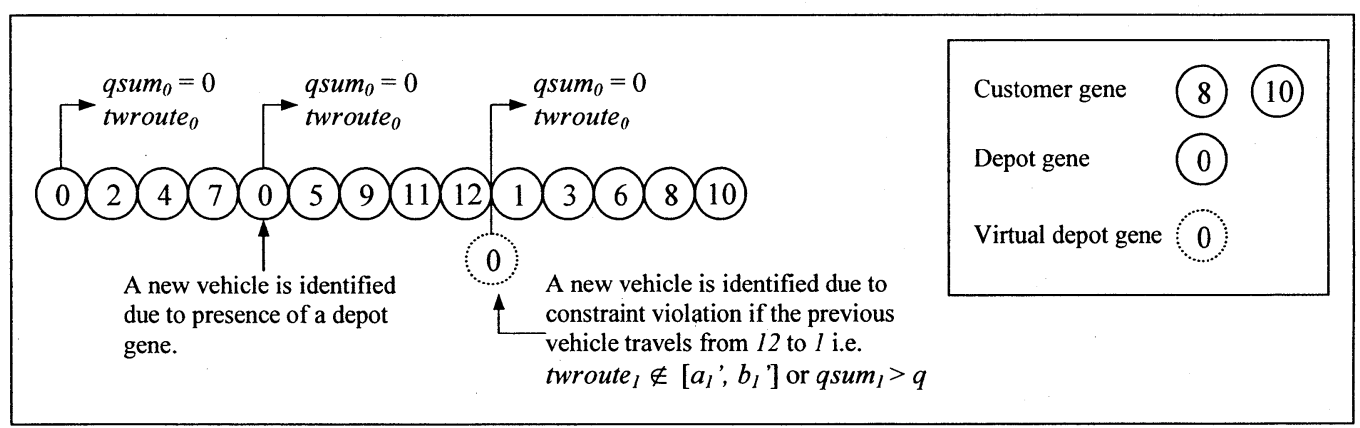

Figure 1. VRPSTW Chromosome Coding and Interpretation in GA

Population size was fixed at 500 and the optimization effort was increased by taking number of generations proportional to the problem size ( $250 \mathrm{x}$ Number of Customers). The initial population was generated using a Stochastic Push Forward Insertion Heuristic (SPFIH) ${ }^{22}$. Furthermore, after every 500 generations population was refreshed keeping the $10 \%$ of the current population.

ii) Genetic Operators: In GA for VRPTW, ordinary crossover and mutation can result in infeasible paths with repeated customers. We used order based crossover and swap mutation to avoid such shortcomings. Simple crossover and mutation techniques were used, such as two point crossover and random position swapping of two elements. The crossover rate was set at $98 \%$, and the mutation rate was $10 \%$ as in the real valued population higher values are advantageous ${ }^{23)-24)}$.

\section{(2) Column Generation}

Column generation or Dantzig-Wolfe decomposition, decomposes the VRPTW problem (1) - (9) into the set partitioning master problem and the subproblem of Elementary Shortest Path Problem with Resource Constraints (ESPPRC). The ESPPRC is a NP-hard problem in strong sense $\mathrm{e}^{25}$, it gives the feasible shortest path subjected to the constraints (3) - (9). The master problem, which now consists of selecting a set of feasible paths of minimum cost, is mathematically described in Feillet $e t \mathrm{al}_{.}^{20)}$ as:

$$
\min \sum_{p \in P} c_{p} y_{p}
$$

subject to

$$
\begin{aligned}
& \sum_{p \in P} a_{i p} y_{p}=1 \quad \forall i \in C \\
& y_{p} \in\{0,1\} \quad \forall p \in P
\end{aligned}
$$


Where $y_{p}$ takes value 1 if the path $p$ is selected and 0 otherwise. The cost of the path $p$ is given by $c_{p}$ and $a_{i p}$ represents the number of times path $p$ serves customer $i . P$ is the set of all feasible paths. In actual applications, the set covering master problem is solved by replacing constraint (14) by (16), as linear programming relaxation of set covering type master problem is more stable than set partitioning type ${ }^{17)}$.

$$
\sum_{p \in P} a_{i p} y_{p} \geq 1 \quad \forall i \in C
$$

This study uses an adaptation of ESPPRC algorithms given by Feillet $e t a l .{ }^{20)}$ and Irnich and Villeneuve ${ }^{19)}$, to generate columns for a set covering master problem. At this stage, hard time window variant is considered where delivery is not possible outside the time windows. Vehicle is allowed to wait at no cost if it arrives earlier than start time window of customer. This permits to exclude all the arcs $(i, j)$ which do not satisfy the inequality $a_{i}+t_{i j} \leq b_{i}$. Figure 2 shows the flow chart of the column generation algorithm.

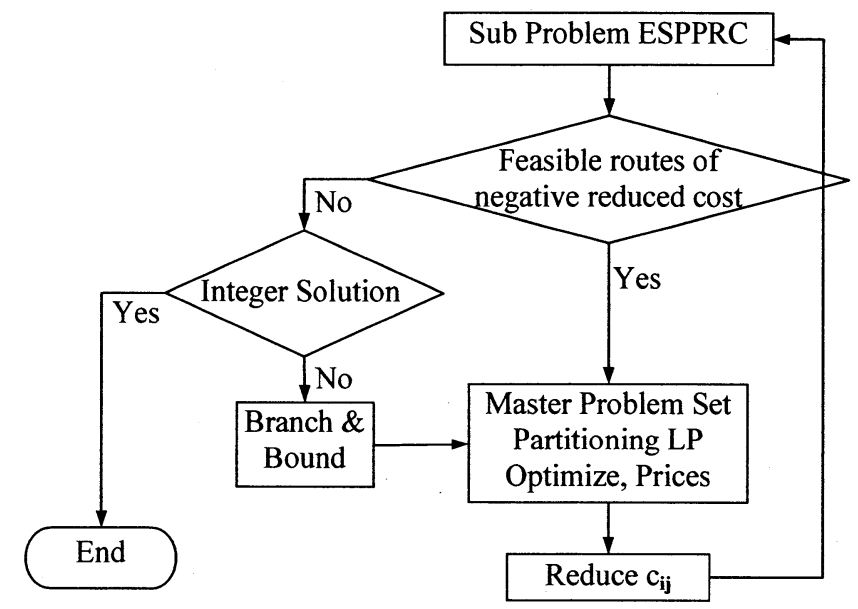

Figure 2. Flow Chart of Column Generation Algorithm

\section{Test Scenarios}

As mentioned earlier, most of the present research on exact approaches allows waiting without any penalty cost. We have defined four different time windows settings based on waiting time being penalized or not. In true Hard Time Windows (HTW) delivery was restricted only within the time windows, thus no waiting or delay was allowed (Figure 3). Whereas in true Soft Time Windows (STW) both early arrival as well as delay penalties were taken into account (Figure 4). Two more scenarios are formed by allowing waiting without penalty for the HTW and STW resulting in Semi Hard Time Windows (SHTW) (Figure 5) and Semi Soft Time Windows (SSTW) (Figure 6), respectively. An upper limit of penalty cost equivalent to a dedicated route serving only the concerned vertex was imposed on both early arrival and late arrival penalties. These limits provides the relaxed time windows $\left(a_{i}{ }^{\prime}, b_{i}{ }^{\prime}\right)$, higher limits would result in virtually unconstrained problems whereas problem tends towards hard time windows as the limits get smaller. Moreover, the early arrival penalty was taken equal to the Vehicle Operating Cost (VOC) and the late arrival penalty was equal to five times of VOC. Heuristic (GA) solution was found for all the time window scenarios whereas at present exact solution (Column Generation) is only available for Vehicle Routing and scheduling with Semi Hard Time Windows (VRPSHTW).

We used C101 and R101 in Solomon's benchmark instances ${ }^{26)}$. These instances are the most widely used test instances in VRPTW-related research to test the worst-case behavior of various algorithms. In C101 (Figure 7) customers are clustered geographically and they have wider time windows centered at the arrival time at various customer vertices. Whereas in R101 (Figure 8) customers are located at random with tight time windows also generated randomly. We tested two more types of instances derived from $\mathrm{C} 101$, by reducing the time window widths to one third of original and by increasing the travel time (thus travel cost) of $20 \%$ of the network links selected at random, by $25 \%$ of its original value. Smaller test instances are 
composed of 25 and 50 customers each and were taken from original 100 customer instances by considering the first 25 and 50 customers, respectively.

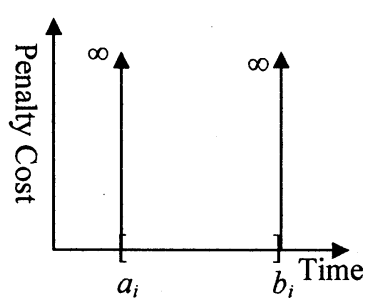

Figure 3. Penalty Function for VRPHTW

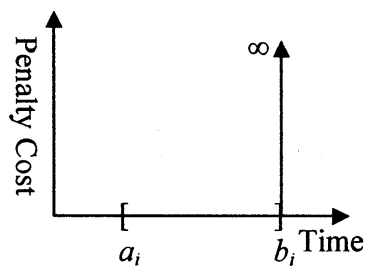

Figure 5. Penalty Function for VRPSHTW

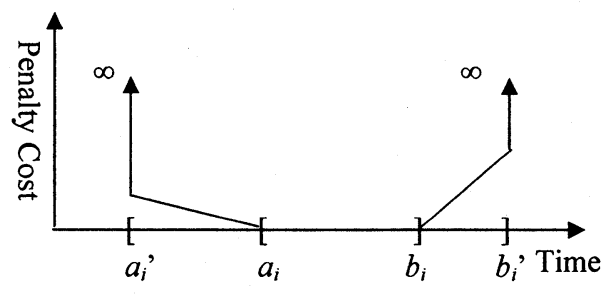

Figure 4. Penalty Function for VRPSTW

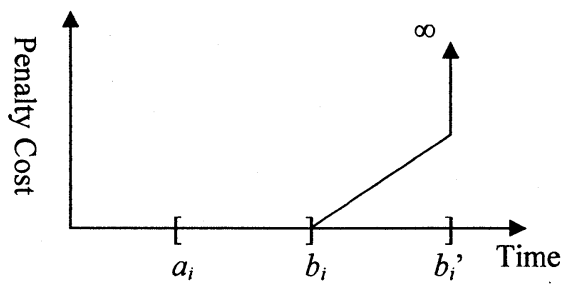

Figure 6. Penalty Function for VRPSSTW

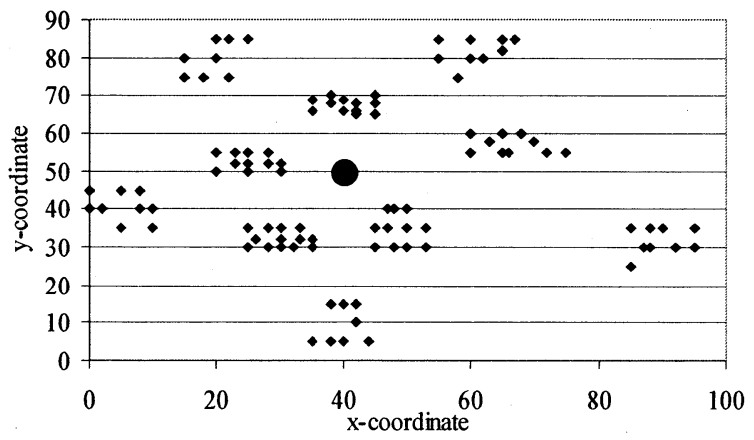

Figure 7. Customer Locations in C101 Solomon's Benchmark Instance

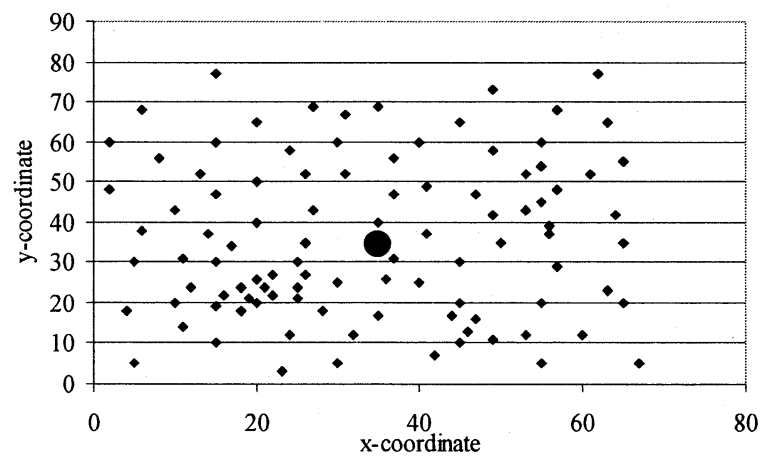

Figure 8. Customer Locations in R101 Solomon's Benchmark Instance

\section{Results and Discussions}

Travel time, solution cost, emissions of NOx, SPM and $\mathrm{CO}_{2}$ were used to compare the approximate solutions of VRPSTW with GA and exact solutions of VRPHTW. Table 1 gives comparison of travel time 
and solution cost, between heuristic solution of VRPSSTW and VRPSHTW's heuristic and exact solution. In Solomon's benchmark instances, distance and travel time between customer vertices are usually taken as their Euclidean distance. Travel time column represents only the running time excluding service as well as waiting time. Solution cost represents fixed cost of vehicles, running travel cost for both the VRPSHTW and VRPSSTW, and additional late arrival penalties for VRPSSTW. It was found that semi soft time windows (SSTW) have lesser solution cost for most of the test instances compared with GA solution of semi hard time windows (SHTW), even though the same conclusion can not be made for travel time. Thus, the main feature of reducing the solution cost is due to use of fewer vehicles in semi soft windows environment. As far as the comparison between exact solution of SHTW and heuristic solution of SSTW is concerned, it has its own drawbacks, as there is a gap between exact and heuristic solution of SHTW in larger instances itself. A similar trend could be observed with heuristic solution of SSTW, particularly in larger instances with wider time windows (Original $\mathrm{C} 101$ and $\mathrm{C} 101$ with increased travel times). Nonetheless, even the heuristic solution of SSTW is lesser than the exact solution cost for SHTW in many of the test instances with tighter time windows (Original R101 and C101 with one-third time windows). This leads to the need for an exact approach for VRPSTW as well to fully understand and evaluate the relative advantages or disadvantages of both soft time windows and hard time windows on an equal basis.

Table 1: Comparison of Heuristic and Exact Solutions of VRP-SHTW with Heuristic Solutions of VRP-SSTW

\begin{tabular}{|l|r|r|r|r|r|r|}
\hline \multirow{2}{*}{ Test Instances } & \multicolumn{3}{|c|}{ Travel Time } & \multicolumn{3}{c|}{ Solution cost* } \\
\cline { 2 - 7 } & VRPSHT & VRPSSTW & VRPSHTW & VRPSSTW \\
\cline { 2 - 7 } C101-25 & Exact & GA & GA & Exact & GA & GA \\
\hline C101-50 & 191.3 & 191.3 & 191.3 & 33934.5 & 33934.5 & 33934.5 \\
\hline C101-100 & 362.4 & 362.4 & 362.4 & 57168.4 & 57168.4 & 57168.4 \\
\hline \multicolumn{7}{|c|}{ C101 with one third time windows } \\
\hline C101-25-13 & 298.8 & 299.8 & 254.8 & 66694.2 & 66708.2 & 53654.3 \\
\hline C101-50-13 & 563.4 & 564.4 & 544.9 & 112073.9 & 112087.9 & 90376.0 \\
\hline C101-100-13 & 1307.7 & 1339.1 & 1339.4 & 226684.0 & 227124.2 & 195327.2 \\
\hline \multicolumn{1}{|c|}{ C101 with travel times increased by 25\% for 20\% links selected at random } \\
\hline C101-25-t20 & 204.8 & 204.8 & 231.8 & 34123.8 & 34123.8 & 34502.3 \\
\hline C101-50-t20 & 379.9 & 379.9 & 511.9 & 57413.7 & 57413.7 & 70137.5 \\
\hline C101-100-t20 & 893.6 & 1246.8 & 1059.1 & 127120.8 & 152907.6 & 139963.7 \\
\hline \multicolumn{7}{|c|}{ R101 Customers are located at random geographically } \\
\hline R101-25 & 617.1 & 617.1 & 561.1 & 91991.7 & 91991.7 & 94408.3 \\
\hline R101-50 & 1044.0 & 1055.2 & 1080.3 & 139646.9 & 139803.9 & 137441.7 \\
\hline R101-100 & 1637.5 & 1724.5 & 1603.5 & 231307.8 & 253362.5 & 216262.4 \\
\hline
\end{tabular}

Emissions from automobiles are represented by functions of travel time and running speed. Travel time and running speed depends on the traffic conditions in any real life road network where as in Solomon's bench mark instances it is taken based on Euclidean distance between the vertices. Therefore to calculate environment related evaluation parameters an average running speed of $20 \mathrm{~km} / \mathrm{h}$ is used for small delivery vehicle with capacity of $2000 \mathrm{~kg}$. Fixing the speed at $20 \mathrm{~km} / \mathrm{h}$, the emissions would follow the travel time only, thus these assumptions may not be realistic and it also emphasize the need of some real life instances to be used to analyze the environmental effects more precisely. It is very clear that exact solution is far better than the GA solution for the tested instance. Table 2 gives the comparison of various environmental related evaluation parameters results for VRPSHTW and VRPSSTW. The table shows mixed results for SHTW and SSTW based on only running time and ignoring the waiting time. In practice, usually the delivery vehicles wait along the street sides with their engines on near the next customer to be serviced, continuously causing the pollutant emissions. Table 3 shows the comparison between true soft time windows and SHTW with regard to emissions when the waiting time (from Table 4) is taken into consideration. Figure 9 shows a graphical representation of this comparison with regard to emission of NOx. It can be observed that soft time windows perform much better environmentally due to their less waiting time. 
Table 2: Comparison of NOx, SPM and $\mathrm{CO}_{2}$ for Soft and Hard Time Windows

\begin{tabular}{|l|c|c|c|c|c|c|c|c|c|}
\hline \multirow{3}{*}{ Test Instances } & \multicolumn{3}{|c|}{ NOx (Kg) } & \multicolumn{3}{c|}{ SPM $(\mathrm{Kg})$} & \multicolumn{3}{c|}{$\mathrm{CO}_{2}(\mathrm{Kg})$} \\
\cline { 2 - 11 } & VRPSHTW & VRPSSTW & VRPSHTW & VRPSSTW & VRPSHTW & VRPSSTW \\
\cline { 2 - 10 } & Exact & GA & GA & Exact & GA & GA & Exact & GA & GA \\
\hline C101-25 & 13.93 & 13.93 & 13.93 & 2.89 & 2.89 & 2.89 & 13.13 & 13.13 & 13.13 \\
\hline C101-50 & 26.36 & 26.36 & 26.36 & 5.47 & 5.47 & 5.47 & 24.88 & 24.88 & 24.88 \\
\hline C101-100 & 60.23 & 67.03 & 73.00 & 12.49 & 13.90 & 15.14 & 56.80 & 63.25 & 68.89 \\
\hline \multicolumn{8}{|c|}{ C101 with one third time windows } \\
\hline C101-25-13 & 21.75 & 21.83 & 18.55 & 4.51 & 4.53 & 3.85 & 20.53 & 20.60 & 17.50 \\
\hline C101-50-13 & 41.02 & 41.09 & 39.67 & 8.51 & 8.52 & 8.23 & 38.71 & 38.77 & 37.43 \\
\hline C101-100-13 & 95.20 & 97.49 & 97.51 & 19.75 & 20.22 & 20.22 & 89.84 & 92.00 & 92.02 \\
\hline \multicolumn{8}{|c|}{ C101 with travel times increased by 25\% for 20\% links selected at random } \\
\hline C101-25-t20 & 14.91 & 14.91 & 16.88 & 3.09 & 3.09 & 3.50 & 14.07 & 14.07 & 15.92 \\
\hline C101-50-t20 & 27.66 & 27.66 & 37.27 & 5.74 & 5.74 & 7.73 & 26.10 & 26.10 & 35.17 \\
\hline C101-100-t20 & 65.05 & 90.77 & 77.10 & 13.49 & 18.83 & 15.99 & 61.39 & 85.66 & 72.76 \\
\hline \multicolumn{8}{|c|}{ R101: Customers are located at random geographically } \\
\hline R101-25 & 44.92 & 44.92 & 40.85 & 9.32 & 9.32 & 8.47 & 42.39 & 42.39 & 38.55 \\
\hline R101-50 & 76.00 & 76.82 & 78.65 & 15.76 & 15.93 & 16.31 & 71.72 & 72.49 & 74.22 \\
\hline R101-100 & 119.21 & 125.54 & 116.73 & 24.73 & 26.04 & 24.21 & 112.50 & 118.47 & 110.16 \\
\hline
\end{tabular}

Table 3: Comparison of NOx, SPM and $\mathrm{CO}_{2}$ for SHTW and STW Considering Waiting Time

\begin{tabular}{|c|c|c|c|c|c|c|c|c|c|}
\hline \multirow{3}{*}{ Test Instances } & \multicolumn{3}{|c|}{ NOx $(\mathrm{Kg})$} & \multicolumn{3}{|c|}{ SPM (Kg) } & \multicolumn{3}{|c|}{$\mathrm{CO}_{2}(\mathrm{Kg})$} \\
\hline & \multicolumn{2}{|c|}{ VRPSHTW } & \multirow{2}{*}{$\frac{\text { VRPSTW }}{\text { GA }}$} & \multicolumn{2}{|c|}{ VRPSHTW } & \multirow{2}{*}{$\frac{\text { VRPSTW }}{\text { GA }}$} & \multicolumn{2}{|c|}{ VRPSHTW } & \multirow{2}{*}{$\frac{\text { VRPSTW }}{\text { GA }}$} \\
\hline & Exact & GA & & Exact & GA & & Exact & GA & \\
\hline C101-25 & 46.00 & 46.00 & 27.53 & 9.54 & 9.54 & 5.71 & 43.40 & 43.40 & 25.98 \\
\hline C101-50 & 37.40 & 37.40 & 37.67 & 7.76 & 7.76 & 7.81 & 35.29 & 35.29 & 35.55 \\
\hline $\mathrm{C} 101-100$ & 60.23 & 93.92 & 80.87 & 12.49 & 19.48 & 16.77 & 56.84 & 82.21 & 76.31 \\
\hline \multicolumn{10}{|c|}{ C101 with one third time windows } \\
\hline C101-25-13 & 79.22 & 79.19 & 42.08 & 16.43 & 16.43 & 8.73 & 74.76 & 74.66 & 39.71 \\
\hline C101-50-13 & 197.24 & 128.20 & 57.21 & 40.91 & 26.59 & 11.87 & 186.14 & 120.91 & 53.99 \\
\hline C101-100-13 & 256.37 & 357.08 & 128.72 & 53.17 & 74.07 & 26.70 & 241.93 & 334.82 & 121.47 \\
\hline \multicolumn{10}{|c|}{ C101 with travel times increased by $25 \%$ for $20 \%$ links selected at random } \\
\hline $\mathrm{C} 101-25-\mathrm{t} 20$ & 46.96 & 46.96 & 28.22 & 9.74 & 9.74 & 5.85 & 44.32 & 44.32 & 26.63 \\
\hline $\mathrm{C} 101-50-\mathrm{t} 20$ & 38.50 & 38.50 & 40.80 & 7.98 & 7.98 & 8.46 & 36.33 & 36.33 & 38.51 \\
\hline $\mathrm{C} 101-100-\mathrm{t} 20$ & 65.05 & 150.25 & 89.81 & 13.49 & 31.16 & 18.63 & 61.39 & 117.53 & 84.76 \\
\hline \multicolumn{10}{|c|}{ R101: Customers are located at random geographically } \\
\hline R101-25 & 60.32 & 60.10 & 44.60 & 12.51 & 12.47 & 9.25 & 56.92 & 56.72 & 42.09 \\
\hline R101-50 & 106.47 & 103.73 & 84.54 & 22.08 & 21.51 & 17.53 & 100.47 & 97.11 & 79.77 \\
\hline R101-100 & 168.05 & 188.84 & 135.31 & 34.86 & 39.17 & 28.06 & 158.59 & 172.23 & 127.69 \\
\hline
\end{tabular}

Table 4 gives the waiting time for semi hard time windows using exact and GA approach, and GA solution for soft time windows using both case settings, i.e. when waiting is allowed at no cost (SSTW) and when waiting cause an early arrival penalty (STW). In HTW settings, waiting was not allowed at all. It is evident that heuristic solution of semi soft time windows results in much less waiting time than the heuristic solution of SHTW, whereas it is comparable with the exact solution of SHTW. The lowest waiting times for the test instances were found in true soft time windows environment even lower than the exact solution of SHTW. Reduction in waiting time may not only be translated in savings in labor and vehicle utilization costs; it also has meaningful effect on on-street parking of delivery vehicles in urban areas and on environment related issues as can be seen in Figure 6. Furthermore, if an exact approach could be developed for STW, the waiting time could further be reduced making it more efficient choice both economically as well as environmentally. 


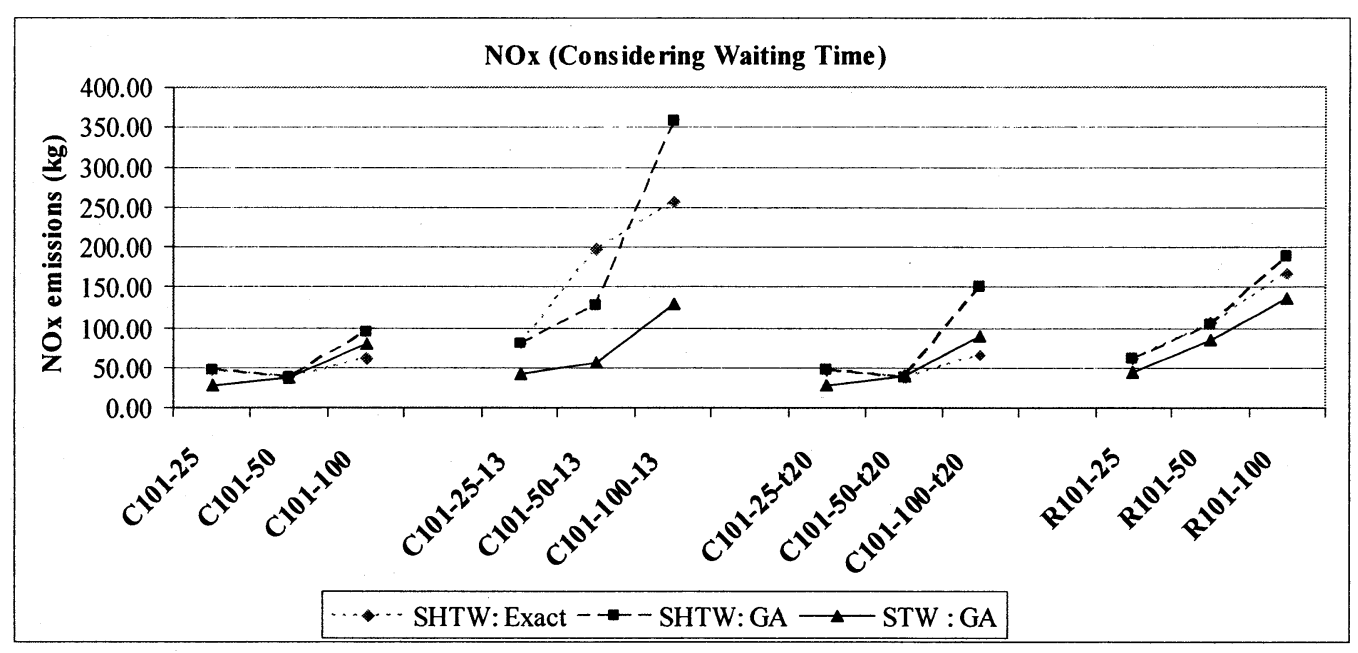

Figure 9. Comparison of NOx emission (considering engine on condition while waiting)

Table 4: Comparison of Waiting Time

\begin{tabular}{|l|l|r|r|r|}
\hline \multirow{2}{*}{$\begin{array}{c}\text { Test } \\
\text { Instances }\end{array}$} & \multicolumn{4}{|c|}{ Waiting Time } \\
\cline { 2 - 5 } & VRPSHTW & VRPSSTW & VRPSTW \\
\cline { 2 - 5 } & GA & Exact & GA & \multicolumn{1}{c|}{ GA } \\
\hline C101 25 & 440.5 & 440.5 & 440.5 & 83.3 \\
\hline C101_50 & 151.3 & 151.3 & 151.3 & 111.1 \\
\hline C101-100 & 369.4 & 0.0 & 499.2 & 0.0 \\
\hline
\end{tabular}

Table 5: Comparison of True STW and HTW

\begin{tabular}{|c|c|c|c|c|}
\hline \multicolumn{2}{|c|}{ Travel Time } & \multicolumn{3}{|c|}{ Solution $\operatorname{cost} * *$} \\
\hline VRPHTW & VRPSTW & VRPHTW & VRPSHTW* & VRPSTW \\
\hline GA & GA & GA & GA & GA \\
\hline 215.2 & 294.8 & 44687.1 & 40110.3 & 35385.6 \\
\hline 494.9 & 406.3 & 69443.5 & 59289.6 & 64010.1 \\
\hline 952.8 & 1110.8 & 138368.3 & 143097.2 & 130208.0 \\
\hline
\end{tabular}

C101 with one third time windows

\begin{tabular}{|l|r|r|r|r|r|r|r|r|r|}
\hline $\mathrm{C} 101-25-13$ & 788.0 & 789.4 & 465.2 & 241.9 & 417.2 & 336.1 & 89189.1 & 77756.0 & 44487.4 \\
\hline $\mathrm{C} 101-50-13$ & 1196.6 & 2146.0 & 1748.6 & 144.2 & 933.7 & 641.7 & 190188.0 & 128864.2 & 86043.8 \\
\hline $\mathrm{C} 101-100-13$ & 3565.9 & 2213.8 & 1770.9 & 232.7 & 1925.0 & 1535.4 & 297843.5 & 277118.1 & 176991.2 \\
\hline
\end{tabular}

C101 with travel times increased by $25 \%$ for $20 \%$ links selected at random

\begin{tabular}{|l|r|r|r|r|r|r|r|r|r|}
\hline C101-25-t20 & 440.3 & 440.3 & 389.7 & 89.0 & 231.9 & 298.6 & 44921.2 & 40296.8 & 36960.0 \\
\hline C101-50-t20 & 148.9 & 148.9 & 381.0 & 66.7 & 607.4 & 493.8 & 71020.7 & 59501.3 & 59945.7 \\
\hline C101-100-t20 & 817.1 & 0.0 & 1050.0 & 99.8 & 1555.8 & 1133.9 & 209327.3 & 164363.4 & 142306.5 \\
\hline \multicolumn{8}{|c|}{$R 101:$ Customers are located at random geographically } \\
\hline R101-25 & 208.5 & 211.5 & 64.3 & 55.7 & 982.1 & 557.0 & 128361.5 & 94914.9 & 67785.7 \\
\hline R101-50 & 369.6 & 418.5 & 210.2 & 100.3 & 1656.3 & 1060.9 & 189901.3 & 144985.7 & 115589.4 \\
\hline R101-100 & 869.5 & 670.9 & 395.6 & 154.7 & 2580.1 & 1703.9 & 296610.5 & 265552.9 & 197974.0 \\
\hline
\end{tabular}

Table 5 compares the travel time and solution cost for true soft time windows with true hard time windows and with SHTW by penalizing its waiting time. For all the instances that are tightly constrained due to time windows, STW have less travel time as compared to the HTW as well as for most of the less constrained instances. As far as the solution cost is concerned, STW is far more economical than HTW, also for many test instances it results in less cost if the waiting is penalized for SHTW.

\section{Conclusion and Future Work}

To analyze the effect of relaxing hard time windows constraint in VRPTW to soft time windows, heuristic algorithm was run on various time windows variants under different scenarios based on time windows width, geographical locations of customers and link travel times along with exact algorithm for SHTW. Analysis results show that relaxing the time windows have better economic and environmental effects on solution of VRPTW. Soft time windows (SSTW and STW) perform much better than hard time windows (SHTW and HTW) in instances, which are tightly constrained due to smaller time windows whereas their performance is 
comparable for less constrained instances. Thus soft time windows can absorb the changes in consumer preferences (by lowering their time windows) in better way than the hard time windows. It was found that not penalizing the waiting time (as in the case of many currently available exact solution techniques for SHTW) results in higher waiting times. Excessive waiting time not only affects the economy of the solution due to extra vehicle and labor hours, it also reduces the environmental viability of the solution as well. Soft time windows on the other hand were found useful in reducing the waiting time and hence were found more environmental friendly.

The analysis presented in this paper was based on benchmark instances and using exact solution only for VRPSHTW. Relaxed soft time windows resulted not only in self-evident results of cost savings but it was also found that these have an improving effect on environmental related issues. There exists a great deal of interest if some exact approach could be formulated for VRPSTW and if the analysis is based on some practical logistics problems. This would help in more precisely recognizing the benefits of soft time windows and actual traffic data would allow finding the realistic emissions analysis based on the prevalent traffic situations. Therefore, future studies will be focused on to incorporate soft time windows constraints in exact solution technique of VRPTW, and apply that model to some practical problems, which are often set in soft time windows environment.

\section{References:}

1) Taniguchi, E., Thompson, R.G., Yamada, T. and Van Duin J.H.R : City Logistics; Network Modeling and Intelligent Transport Systems, Pergamon, Oxford, 2001.

2) Taniguchi, E. and Kakimoto, Y.: Effects of e-commerce on urban distribution and the environment, Journal of the Eastern Asia Society for Transportation Studies, Vol.5, pp. 2355-2366, 2003.

3) Taniguchi, E. and Ando, N.: An experimental study on the performance of probabilistic vehicle routing and scheduling with ITS, in Recent Advances in City Logistics proceedings of the 4th International Conference on City Logistics, Langkawi, Malaysia, 2005, Taniguchi , E. and Thompson, R.G. eds., Elsevier, Oxford, pp. 59-73, 2005.

4) Qureshi, A. and Hanaoka, S.: Analysis of the effects of cooperative delivery system in Bangkok, in Recent Advances in City Logistics proceedings of the 4th International Conference on City Logistics, Langkawi, Malaysia, 2005, Taniguchi , E. and Thompson, R.G. eds., Elsevier, Oxford, pp. 293-306, 2005.

5) Badeau, P., Guertin, F., Gendreau, M., Potvin, J. and Taillard, E.: A parallel tabu search heuristic for the vehicle routing problem with time windows, Transportation Research (C), Vol.5(2), pp. 109-122, 1997.

6) Taillard, E., et al.: A tabu search heuristic for the vehicle routing problem with soft time windows, Transportation Science, Vol.31(2), pp. 170-186, 1997.

7) Sadeh, N.M., Nakakuki, y. and Thangiah, S.R.: Learning to Recognize (un)Promising Simulated Annealing Runs: Efficient Search Procedures for Job Shop Scheduling and Vehicle Routing, Annals of Operations Research Vol. 75, pp. 189-208, 1997.

8) Taniguchi, E. and Thompson, R.G.: Modeling city logistics, Transportation Research Records, Vol. 1790, pp. 45-51. 2002.

9) Qureshi, A.: Analysis of the Effects of Cooperative Delivery System in Bangkok, AIT Thesis No. TE04-10, 2005.

10) Tavares J., Pereira, F.B., Machado, P. and Costa, E: GVR delivers it on time, 4th Asia Pacific Conference on Simulated Evolution and Learning (SEAL'02), Singapore 2002.

11) Tan, K.C., Lee, L.H. and Ou, K.: Artificial intelligence heuristics in solving vehicle routing problems with time window constraints, Engineering Applications of Artificial Intelligence, Vol.14, pp. 825-837, 2001.

12) Tan, K.C., Lee, L.H. and Ou, K.: Heuristic methods for vehicle routing problem with time windows, Engineering Applications of Artificial Intelligence, Vol.15, pp. 281-295, 2001.

13) Thompson, R.G. and Van Duin, J.H.R.: Vehicle routing and scheduling, in Innovations in Freight Transportation, Taniguchi, E. and Thompson, R.G. eds., WIT Press, Southampton, pp. 47-63, 2003.

14) Kolen, A. W. J., Rinnooy Kan, A.H.G. and Trienekens, H.W.J.M.: Vehicle routing with time windows, Operations Research, Vol.35(2), pp. 266-273, 1987.

15) Fisher, M.L., Jornsten, K.O. and Madsen, O.B.G.: Vehicle routing with time windows - Two optimization algorithms, Operations Research, Vol.45(3), pp. 488-498, 1997. 
16) Kallehauge, B., Larsen, J. and Madsen, O.B.G.: Lagrangian duality applied to the vehicle routing problem with time windows, Computers \& Operations Research Vol.33, pp. 1464-1487, 2006.

17) Desrochers, M., Desrosiers, J. and Solomon, M.: A new optimization algorithm for the vehicle routing problem with time windows, Operations Research, Vol.40(2), pp. 342-354, 1992.

18) Kohl, N., Desrosiers, J., Madsen, O.B.G., Solomon, M.M. and Soumis, F.: 2-Path cuts for the vehicle routing problem with time windows, Transportation Science, Vol.33(1), pp. 101-116, 1999.

19) Irnich, S., and Villeneuve, D.: The Shortest Path Problem with K-Cycle Elimination (K3): Improving a Branch and Price Algorithm for the VRPTW, Technical Report G-2003-55, GERAD, 2003.

20) Feillet, D., Dejax, P., Gendreau, M. and Gueguen, C.: An exact algorithm for the elementary shortest path problem with resource constraints: Application to some vehicle routing problems, Networks, pp. 216-229, 2004.

21) Chabrier, A.: Vehicle routing problem with elementary shortest path based column generation, Computers \& Operations Research Vol.33, pp. 2972-2990, 2006.

22) Alvarenga, G.B. and Mateus, G.R.: A two-phase genetic and set portioning approach for the vehicle routing problem with time windows, in Proceedings of the Fourth International Conference on Hybrid Intelligent Systems (HIS'04), IEEE, 2004.

23) Wright A.H.: Genetic algorithms for real parameter optimization, in Foundation of Genetic Algorithms, Rawlins, J.E. eds., Morgan Kaufmann, USA, pp. 205-218, 1991.

24) Janikow, C.Z. and Michalewicz, Z.: An experimental comparison of binary and floating point representation in genetic algorithms, in Proc. International Conference on Genetic Algorithm (ICGA 4), Richard, K.B. \& Calson, B.B., eds., Morgan Kaufmann, USA, pp 31-36, 1991.

25) Dror, M.: Note on the complexity of the shortest path models for column generation in VRPTW, Operations Research, Vol.42(5), pp. 977-978, 1994.

26) Solomon, M. M.: Algorithms for the vehicle routing and scheduling problem with time windows constraints, Operations Research, Vol.35(2), pp. 254-265, 1987.

\title{
EFFECTS OF RELAXING TIME WINDOWS ON VEHICLE ROUTING AND SCHEDULING
}

\author{
By Ali Gul Qureshi **, Eiichi Taniguchi*** and Tadashi Yamada****
}

City Logistics deals with measures such as route optimization to mitigate typical problems caused by urban goods movement. While many real life logistics problems use soft time windows, most of the exact route optimization research considers hard time windows. This paper focuses on the effects of relaxing hard time windows constraints to soft time windows. A variety of time windows variants are analyzed under different scenarios based on time windows width, geographical locations of customers and link travel times. It was found that relaxing the time windows have better economic and environmental effects on solution of VRPTW.

\section{配車配送における到着時刻指定の緩和の影響分析*}

クレシ・アリ**・谷口栄一***・山田忠史****

都市物流に関する問題の一因は、顧客の到着時刻指定が厳しいことにあると言われてい る。そこで、本論文では、到着時刻指定が緩和されることの影響について、時間枠付きの 配送計画問題を用いて分析を行った。到着時刻指定の種類（ソフト、ハード、セミソフト、 セミハード）、指定時間帯の大きさ、顧客の位置、リンク走行時間などを変化させること により、いくつかのシナリオを設定し、検討を行った。分析の際には、問題の種類に応じ て、厳密解法と近似解法を適宜使用した。計算結果から、到着時刻指定を緩和することが、 集配送費用や環境負荷の抑制に効果的であることが示唆された。 